\title{
ARTIGO
}

DOI: https://doi.org/10.22481/praxis.v15i31.4682

\section{DISCUTINDO CONCEPÇÕES SOBRE SEXUALIDADE INFANTIL: UM TEMA DELICADO}

\author{
DISCUSSING CONCEPTIONS ON CHILD SEXUALITY: A DELICATE THEME
}

DISCUTIENDO CONCEPCIONES SOBRE SEXUALIDAD INFANTIL: UN TEMA

DELICADO

\author{
Litiéli Wollmann Schutz \\ Universidade Federal de Santa Maria - Brasil \\ Lucas da Silva Martinez. \\ Universidade Federal de Santa Maria - Brasil \\ Sueli Salva \\ Universidade Federal de Santa Maria - Brasil
}

\begin{abstract}
Resumo: Esta pesquisa objetiva analisar as concepções construídas por três professoras da rede privada de um município do Rio Grande do Sul, no nível da educação infantil, em relação às manifestações da sexualidade infantil. Desde muito pequenas as crianças expressam curiosidades sobre o seu corpo e o corpo dos outros, exploram e descobrem o que lhes causam dor, prazer e desconforto. As concepções acerca da temática, ainda se configuram como algo assustador e proibido, fazendo com que a sexualidade infantil, permaneça, na maioria das vezes uma incógnita ao olhar adulto. Os estudos teóricos estão baseados em Louro (2008), Schindhelm (2013), Weeks (2000) entre outros e outras. Essa pesquisa caracteriza-se como qualitativa de cunho exploratório, tendo como principal ferramenta para a produção dos dados a entrevista desencadeada a partir de palavras e imagens utilizadas como evocadoras de memória. O resultado do processo foi organizado a partir de narrativas das professoras, e a análise centrou-se no destaque de percepções, concepções e ideias que as professoras foram expressando em suas entrevistas. Como resultados da pesquisa pode-se perceber que a discussão sobre sexualidade infantil está repleta de preconceitos e tabus. As professoras não se sentem preparadas para trabalhar esses aspectos com as crianças. Os espaços para a discussão e reflexão sobre a sexualidade infantil são quase inexistentes, prevalecendo o não dito.
\end{abstract}

Palavras-chave: Crianças. Educação infantil. Sexualidade infantil.

Abstract: This research aims to analyze the conceptions raised by three female teachers of the private school from Rio Grande do Sul state, at the child education level, in respect to the manifestations of children sexuality. From a very young age children express curiosities about their bodies and the bodies of others, explore and discover what causes them pain, pleasure and discomfort. The conceptions about the theme, are still configured as something frightening and forbidden, making that the infantile sexuality, remain, most of the time as something unknown at the adult perception. The theoretical studies are based on Louro (2008), Schindhelm (2013), Weeks (2000) among others. This 
research is characterized as qualitative of exploratory nature, having as main tool for the data production the interview triggered from words and images used as memory evocative. The result of the process was organized from the teachers' narratives, and the analysis focused on highlighting the perceptions, conceptions and ideas that the teachers expressed in their interviews. As research results it can be seen that the discussion about child sexuality is full of on prejudices and taboos. Teachers do not feel prepared to work on these aspects with children. The spaces for discussion and reflection on child sexuality are almost non-existent, prevailing the unspoken.

Keywords: Children. Child education. Child sexuality.

Resumen: Esta investigación objetiva analizar las concepciones construidas por tres profesoras de la red privada de un municipio de Rio Grande do Sul, en el nivel de la educación infantil, en relación a las manifestaciones de la sexualidad infantil. Desde muy pequeños los niños expresan curiosidades sobre su cuerpo y el cuerpo de los demás, exploran y descubren lo que les causan dolor, placer e incomodidad. Las concepciones acerca de la temática, aún se configuran como algo espeluznante y prohibido, haciendo que la sexualidad infantil, permanezca, la mayoría de las veces una incógnita al mirar a la mirada adulta. Los estudios teóricos se basan en Louro (2008), Schindhelm (2013), Weeks (2000) entre otros y otras. Esta investigación se caracteriza como cualitativa de cuño exploratorio, teniendo como principal herramienta para la producción de los datos la entrevista desencadenada a partir de palabras e imágenes utilizadas como evocadoras de memoria. El resultado del proceso fue organizado a partir de narrativas de las profesoras, y el análisis se centró en el destaque de percepciones, concepciones e ideas que las profesoras fueron expresando en sus entrevistas. Como resultados de la investigación se puede percibir que la discusión sobre sexualidad infantil está repleta de prejuicios y tabúes. Las profesoras no se sienten preparadas para trabajar esos aspectos con los niños. Los espacios para la discusión y reflexión sobre la sexualidad infantil son casi inexistentes, prevaleciendo lo no dicho.

Palabras clave: Niños. Educación infantil. Sexualidad infantil.

\section{Para pensar a sexualidade na educação infantil - introduzindo o tema}

Pensar sobre a sexualidade na educação infantil implica trabalhar com a quebra de tabus, preconceitos e diferentes visões sobre o assunto, pois, muitas vezes, a sexualidade infantil é encarada pelos adultos como se não existisse ou como se fosse um aspecto de pouca importância para o desenvolvimento da criança, ou ainda, como se fosse um problema. Partimos do pressuposto que sexualidade pode ser compreendida como "[...] uma invenção social, uma vez que se constitui, historicamente, a partir de múltiplos discursos sobre o sexo: discursos que regulam, que normatizam, que instauram saberes, que produzem 'verdades' [...]” (LOURO, 2000, p. 6) e sobre esse processo de normatização, segunda a autora, a escola entende bem. Os discursos sobre a sexualidade produzem continuamente modos diferentes de compreendê-la. Além disso, parece ser assunto para todos, muitas vezes, de forma equivocada e que gera consequências. "A evidência da sexualidade na mídia, nas roupas, nos shoppingcenters, nas músicas, nos programas de TV e em outras múltiplas situações experimentadas 
pelas crianças e adolescentes vem alimentando o que alguns chamam de "pânico moral"" (LOURO, 2000, p. 18).

O "pânico moral" produz silenciamento, produz certa dificuldade de tratar o tema da sexualidade de forma aberta e compreensível. Weeks (2000, p. 25) argumenta que:

O corpo biológico é o local da sexualidade, estabelecendo os limites daquilo que é sexualmente possível, a sexualidade é mais do que simplesmente o corpo. [...] A sexualidade tem tanto a ver com nossas crenças, ideologias e imaginações quanto com nosso corpo físico.

Sendo o corpo o lugar da sexualidade, embora não seja limitada a ele, quem nasce, nasce com um corpo e, portanto, com sexualidade ambos construídos pela linguagem que expressa nossas crenças, ideologias, discursos, imaginação, portanto, a criança não pode ser pensada como sujeito sem sexualidade.

Na educação infantil, quando nos referimos à criança, podemos entender a sexualidade como um aspecto importante da corporeidade voltado tanto para as descobertas anatômicas que as crianças realizam como também para conhecer-se e através do toque, compreender o que lhes causa sensação de conforto, prazer, o que lhes causa dor e desconforto, embora para as professoras o fato da criança tocar o corpo não é visto como momento de descoberta, mas como um problema que necessita de controle e vigilância. A sexualidade é também o que se diz discursivamente sobre ela. "A sexualidade, portanto, não é somente um fato natural, é também, e, sobretudo, um fato cultural e como tal envolve as relações entre as pessoas, toca o mundo das emoções e do conhecimento" (CAMEROTTO; FORNASIER; ZABALZACERDEIRIÑA, 2017, p. 147, tradução nossa ${ }^{1}$ ), sugerem as autoras que o trabalho sobre sexualidade com as crianças envolve o conhecimento científico nas possíveis explicações, mas precisa envolver, sobretudo, a afetividade e o respeito às diferenças culturais.

As identidades de gênero, um tema que frequentemente aparece nas discussões também está relacionado com a sexualidade, mas são coisas distintas.

\footnotetext{
A inscrição dos gêneros - feminino ou masculino — nos corpos é feita, sempre, no contexto de uma determinada cultura e, portanto, com as marcas dessa cultura. As possibilidades da sexualidade - das formas de expressar os desejos e prazeres também são sempre socialmente estabelecidas e codificadas. As identidades de gênero e sexuais são, portanto, compostas e definidas por relações sociais, elas são moldadas pelas redes de poder de uma sociedade (LOURO, 2000, p. 6).
}

\footnotetext{
${ }^{1}$ No original: "La sessualità infatti, non è solo un fatto naturale, è anche e soprattutto un fatto culturale e come tale chiama in gioco le relazioni tra le persone, va a toccare il mondo delle emozioni e delle conoscenze".
} 
O interesse por pesquisar essa temática se deu durante as vivências do estágio extracurricular de uma das autoras do artigo, realizado em uma instituição privada em um município do Rio Grande do Sul. As professoras ${ }^{2}$ atuantes nesse ambiente, traziam inúmeros relatos e dúvidas sobre a temática que decorriam de suas observações no berçário onde havia crianças que se masturbavam, segundo elas, sempre que estavam ansiosas.

Compreender o que a temática sexualidade infantil suporta, ainda nos dias de hoje, é um grande desafio, pois, os espaços institucionais para a discussão e reflexão são pouco visíveis. Mesmo que os aprofundamentos teóricos em relação ao tema venham aumentando, pode-se dizer que esse ainda é um tema de difícil discussão e poucas vezes colocado em pauta para estudos e reuniões pedagógicas das instituições de educação infantil, uma vez que muitas consideram que sexualidade é um tema para os adultos e a sexualidade entendida como algo que pode apenas ser manifestada por pessoas adultas.

Segundo as Diretrizes Curriculares Nacionais para a Educação Infantil (DCNEI) em seu artigo 9, inciso I (BRASIL, 2009), as práticas pedagógicas na Educação Infantil precisam garantir experiências que: "Promovam o conhecimento de si e do mundo por meio da ampliação de experiências sensoriais, expressivas, corporais que possibilitem movimentação ampla, expressão da individualidade e respeito pelos ritmos e desejos da criança”. Neste sentido, a vivência de experiências é fundamental para que a criança possa conhecer-se e necessita para isso ser encorajada a explorar o ambiente e se expressar por meio das múltiplas linguagens: “[...] expressiva, comunicativa, simbólica cognitiva, ética metafórica, lógica, imaginativa e relacional" (EDWARDS; GANDINI; FORMAN, 2016, p. 23).

A pesquisa que originou o artigo teve como objetivo analisar as concepções construídas por três professoras que atuam na educação infantil, em relação às manifestações da sexualidade infantil. Para problematizar o tema e melhor entendê-lo, apostou-se em desenvolver uma pesquisa qualitativa em uma instituição da rede privada em um município do $\mathrm{RS}^{3}$. A escolha das professoras se deu pelo aceite das mesmas para falar sobre o tema e por terem expresso dificuldades para atuar diante da existência da manifestação da sexualidade infantil pelas crianças no cotidiano escolar e pela própria dificuldade de tratar o tema.

Este artigo aborda no primeiro momento os caminhos metodológicos, posteriormente serão discutidos alguns conceitos que sustentarão as análises.

\footnotetext{
${ }^{2}$ Será utilizada durante a escrita desse artigo a palavra professora, pois, as participantes da pesquisa são todas do sexo feminino. A linguagem feminina predomina no trabalho em detrimento da grande quantidade de autoras citadas.

${ }^{3}$ A instituição foi escolhida em detrimento da participação de uma das autoras na referida instituição, na condição de estagiária.
} 


\section{Os Caminhos Metodológicos}

Essa pesquisa se alinha com princípios da pesquisa qualitativa. Embora ela seja criticada por seu empirismo e pela sua "falta de objetividade" (MINAYO, 2001), neste trabalho ela se mostra como a mais adequada, pois os resultados estão interligados a uma gama de significados, sentimentos e sentidos a qual a pesquisa qualitativa permite investigar, proporcionando assim, um entendimento mais aprofundado dos aspectos buscados. A pesquisa se caracteriza como exploratória, pois, segundo Gil (2002, p. 37) “[...] este tipo de pesquisa tem como objetivo proporcionar maior familiaridade com o problema, com vistas a torná-lo explicito ou para construir hipóteses [...]" e envolve os seguintes passos: a) levantamento bibliográfico; b) entrevistas e estudos com as professoras que tiveram experiências práticas com o problema pesquisado; c) análise de suas concepções que estimulem a compreensão do tema estudado.

Durante o processo investigativo dessa pesquisa utilizou-se a entrevista como técnica para a produção de dados. Para Gil (2002), a entrevista é, entre todas as técnicas de interrogação, a que mais possui flexibilidade. É a técnica que o/a investigador/a se apresenta frente ao investigado e formula questionamentos para obter os dados que interessam a investigação. As entrevistas foram realizadas com três professoras de uma escola de educação infantil da rede privada de um município do Rio Grande do Sul e para desencadear a conversa durante as entrevistas elegemos algumas palavras e imagens como evocadoras de memória.

Tratar o tema sexualidade é complexo por ser considerado um tabu e que envolve outros aspectos do sujeito como crença, educação, valores morais, cultura, etc. Em decorrência dessa complexidade optou-se por elaborar, no lugar de um roteiro com perguntas definidas, um acervo de palavras e imagens utilizadas como "evocadoras de memória" para desencadear as falas das professoras e para que elas se sentissem à vontade para dialogar sobre o tema. A escolha das palavras e imagens estava relacionada a alguns comentários feitos pelas professoras nos momentos de convívio com uma das autoras, o que também despertou interesse para estudar o tema. O material foi disposto em envelopes e eram retirados por elas de forma aleatória. Havia o mesmo número de palavras ${ }^{4}$ e imagens ${ }^{5}$ e o início deu-se pelas imagens. As professoras retiravam as imagens e as palavras, dialogando livremente sobre o

\footnotetext{
4 As palavras que continham nos envelopes eram: sexualidade infantil, masturbação, crianças, infâncias, brincadeiras, interação e educação infantil.

${ }^{5}$ Os envelopes continham imagens de crianças demonstrando curiosidade em relação ao corpo, seu e de outras crianças, de crianças se masturbando, de crianças com os corpos expostos.
} 
que retiravam dos envelopes tendo como base a experiência vivida com as crianças na educação infantil. Os dados foram registrados a partir da gravação em áudio. Ao finalizar as entrevistas, a pesquisadora questionou-as sobre os aspectos da formação das mesmas, sobre a existência do embasamento teórico, ou espaço para a discussão e reflexão da temática durante a formação inicial ou em momentos de formação continuada. As três professoras negaram a existência de espaços e momentos de discussão da temática sexualidade infantil durante a formação inicial.

A partir das entrevistas as professoras construíram narrativas, pois, segundo Clandinin e Connelly (2015), a melhor forma de estudar a experiências de pessoas é através das suas narrativas. Narrar é uma forma de organização do pensamento, é uma forma de fazer existir através de fatos contados. Melucci (2005) ressalta que cada vez mais a pesquisa em educação valoriza as narrativas individuais, porque estas comportam a dimensão macroestrutural da sociedade. Assim, para os autores destacados, não importa tanto a quantidade de participantes, mas sim, a riqueza do que estes têm a narrar.

A participação das professoras foi de forma voluntária, pois dentre todas que atuam nos dois turnos da escola pesquisada (manhã e tarde), apenas três aceitaram. A possível causa deste fato pode estar diretamente relacionada à temática discutida, pois, momentos antes de serem questionadas se aceitavam ou não serem entrevistadas, as professoras perguntavam qual seria o tema da pesquisa. Sendo este sobre sexualidade infantil, percebia-se um desconforto fazendo com que negassem a sua participação.

As professoras participantes, todas com formação superior, apresentavam diferentes idades e optaram por usar pseudônimos para manter suas identidades protegidas. Foram denominadas assim: Maria (41 anos), que atua há 20 anos como professora de educação infantil; Isabella (27 anos), que atua há 6 anos como professora de educação infantil e Josefina (23 anos), que atua há 6 meses como professora na educação infantil.

Para analisar os dados, buscaram-se percepções, concepções e ideias emitidas pelas professoras durante a entrevista, que podem ajudar a esclarecer o tema da sexualidade infantil e compreendê-las à luz de teóricas e teóricos que abordam o tema, como, por exemplo, Guacira Lopes Louro (2000; 2008); Virginia Schindhelm (2013) Jeffrey Weeks (2000) entre outros e outras.

A seguir será realizada uma análise dos dados produzidos pelas professoras, baseados em autores que discutem a temática. 


\section{Sexualidade Infantil: Algo fora do tempo?}

A sexualidade infantil, ainda nos dias de hoje, é uma temática pouca discutida e de difícil abordagem, pelos desafios e inquietações que promove no contexto escolar e na sociedade por estar envolto de silenciamentos. Freud foi um dos precursores da temática e mais contemporaneamente temos a importante contribuição de Foucault (1988) em História da Sexualidade. O segundo tornou-se uma das referências mais importantes dos estudos sobre gênero e sexualidade no Brasil.

No início do século passado, Freud mostrou em seus estudos a existência da sexualidade na infância. Segundo Freud (1969) a criança possui uma curiosidade natural, mostra-se curiosa em relação ao seu corpo e ao corpo do outro. Os estudos de Freud sobre sexualidade infantil, ao propor que esta se inicia ainda na infância, geraram conflitos com a visão de ingenuidade imposta à criança da época. Freud (1969) foi o primeiro autor a descrever que a criança é dotada de desejos, sensações, afetos e conflitos, abrindo, assim, indagações para estudos e discussões sobre sexualidade infantil.

Para Britzman (1998, p. 162) "[...] a sexualidade está presente e faz parte da nossa vida, podendo ser vista como a base da curiosidade e a força que nos permite elaborar e ter ideias". Schindhelm (2013), com base nos estudos de Michel Foucault destaca que o termo sexualidade surge, no início do século XIX, de modo a estabelecer relações, primeiramente, com o desenvolvimento de diversos campos de conhecimentos, que abordavam os mecanismos biológicos de reprodução e as variantes individuais ou sociais do comportamento.

O termo sexualidade veio seguido da introdução de um conjunto de regras e de normas, das quais parte compactuava com uma visão tradicional e parte compactuava com novas concepções acerca da sexualidade, apoiada nas instituições religiosas, judiciárias, pedagógicas e médicas. E por outra parte, não menos importante, trouxe mudanças no modo pelo qual os indivíduos são levados a dar sentido e valor à sua conduta, seus deveres, prazeres, sentimentos, sensações e sonhos.

A sexualidade é um conceito historicamente construído e pode ser abordada por diferentes perspectivas, significados e conteúdos. Assim, também o entendimento sobre sexualidade varia dependendo da época e cultura a qual está inserida, dessa forma, é difícil obter-se uma visão única sobre o conceito. Segundo Weeks (2000, p. 38) a sexualidade não é um “[...] domínio unificado [...]”, podendo variar ao longo da história, da cultura e também ao 
longo da vida social dos indivíduos. A sexualidade é um conceito profundamente problemático e o mesmo aponta desafios, os quais não existem respostas fáceis de serem elaboradas. Sendo assim, falar sobre ou conceituar o termo sexualidade se torna uma tarefa complexa, até mesmo para os pesquisadores da área (WEEKS, 2000).

Não é de se estranhar, portanto, que as professoras expressem tais complexidades, alguns paradoxos uma vez que não há um modo único de compreender esse conceito, como foi possível observar ao longo do desenvolvimento da pesquisa. Pode-se ver na narrativa de Isabella, que:

A sexualidade se desenvolveria na puberdade, com dez a doze anos, mas além do caso que tive em sala de aula, ouvi outras professoras comentarem de as crianças estarem buscando prazer através de se tocar, ainda novas com apenas dois anos. Sexualidade é isso, tu começar a conhecer o teu corpo e saber o que te dá prazer e na verdade não é uma coisa ruim, mas é muito precoce pra uma criança de dois anos. É tu conhecer teu corpo e dar prazer pra ele $(\text { ISABELLA })^{6}$.

Apesar de compreender e concordar com a existência da sexualidade infantil, para Isabella a sexualidade se desenvolveria na puberdade e não em crianças menores, embora admita que seja a descoberta do corpo, não admite pensar que isso possa ocorrer quando a criança ainda é bem pequena, com dois anos, por exemplo. Para Ribeiro (2009), a sexualidade infantil envolve-se com prazer, o qual favorece a descoberta do corpo e a percepção de que ele proporciona diferentes sensações. Isabella argumenta que a sexualidade está voltada para o conhecimento e a descobertas de sensações prazerosas, pois, através da exploração do corpo, a criança vai conhecendo a si e aos outros. Ao mesmo tempo, percebe-se que ela entra em conflito, porque mesmo admitindo que seja um processo de descoberta, pensa que isso não pode iniciar no começo da vida.

De acordo com os/as autores/as estudados podemos conceber a sexualidade como uma forma de autoconhecimento de descoberta de si, desta forma pode-se pensar que desde o nascimento esse processo já se inicia. Torna-se problemático quando essa descoberta de si adquire contornos que são julgados eróticos, considerado assim, precoce.

Outra professora, a Josefina afirma que sexualidade infantil:

\footnotetext{
${ }^{6}$ Optou-se por dar destaque às narrativas das professoras participantes da pesquisa, através do uso do itálico, diferenciando-as de demais citações de autores.
} 
Tem a ver com sentimentos, com a personalidade de cada criança. É quando a criança começa a perceber, conhecer novas sensações, não tem nada ligado ao sexo. É quando a criança começa a perceber quem é menino e quem é menina e começa se descobrir. Não existe um conceito muito específico sobre este assunto. É uma coisa muito ampla, é bem de sentimentos (JOSEFINA).

Josefina ressalta a ideia de que os sentimentos e sensações estão vinculados diretamente com a sexualidade infantil e destaca a diferença entre sexo e sexualidade. Para a professora a base da sexualidade está na descoberta do corpo, em conhecer o que sente desvinculando do ato sexual em si. A expressão sexo, em muitos momentos foi referida como sinônimo de ato sexual. Sexo pode estar relacionado com o ato, mas pode também, segundo Weeks (2000, p. 29) ser “[...] um termo descritivo para as diferenças anatômicas básicas, internas e externas ao corpo, que vemos como diferenças entre homens e mulheres". Por sua vez, sexualidade está ligada para todos os sentimentos e sensações que o corpo possui, relacionado ao corpo todo, não apenas aos órgãos sexuais. É esta noção que entendemos importante para compreender o que acontece com as crianças.

A professora Maria não quis comentar seu entendimento sobre sexualidade infantil, apenas falou que é um tema muito difícil de ser abordado em sala de aula, entretanto, o seu silêncio é uma evidencia sobre a dificuldade de falar sobre o tema. Para Louro (2008, p. 80), a "[...] sexualidade infantil geralmente não é apresentado de forma aberta [...]" e, ainda hoje convive-se com um silenciamento em torno do mesmo. Sendo assim, a ideia sobre a existência da sexualidade infantil é pouco aceita e discutida pela sociedade. Ressalta-se que enquanto o assunto acerca da sexualidade infantil não for discutido abertamente no meio social sempre será enfatizado como um tema permeado de preconceitos, crenças, tabus e desconhecimentos. Além disso, em tempos de retrocessos no campo político e retorno a pautas conservadoras, o tema ainda gera medo entre professores das escolas, especialmente, escolas infantis.

Não raro, é possível observar as professoras negando o desenvolvimento e manifestação da sexualidade infantil, disso decorre a necessidade de abrir momentos e espaços para discussão sobre a temática. A partir de então, quem sabe, haverá uma maior compreensão sobre o tema, enfatizando que não há uma única resposta para as dúvidas das professoras, mas podem-se buscar coletivamente modos de tratar o tema na educação infantil. Um exemplo de experiência bem sucedida é relatado no artigo de Camerotto, Fornasier e Zabalza-Cerdeiriña 2017), que utilizaram como estratégia para tratar o tema do nascimento das crianças levar para 
a sala de aula duas barrigas (uma rosa e uma marrom para contemplar a diversidade cultural) que simulavam a barriga de mulheres grávidas e dentro das barrigas o cordão umbilical. As barrigas foram colocadas na sala surpreendendo as crianças que foram convidadas a entrar em um jogo, simulando que ainda estavam na barriga da mãe e as professoras assumiram papéis de jornalistas que iriam fazer entrevistas as crianças. Assim as crianças eram envolvidas em jogo que lhes possibilitava falar sobre o nascimento de um bebê. A primeira pergunta foi: “Como fazem as crianças a entrar na barriga da mãe?" (CAMEROTTO; FORNASIER; ZABALZA-CERDEIRIÑA, 2017, p. 147, tradução nossa ${ }^{7}$ ). Para as autoras as barrigas tornam-se "[...] objetos afetivos e instrumentos de jogo e fundo integrador" (CAMEROTTO; FORNASIER; ZABALZA-CERDEIRIÑA, 2017, p. 148, tradução nossa ${ }^{8}$ ). Para as autoras, o fundo integrador é:

[...] um modelo de programação importantíssimo na educação infantil uma vez que as experiências se apresentem no interior de um ciclo emocional que coloca em relação os desejos (expectativas, tensões, motivações) pode agitar, move-se do estado de quietude e das rotinas criando novos entusiasmos, facilita um encontro (com personagens fantásticos, uma pessoa, um livro, uma ação) deixa a criança impressionada como experiência que desperta a curiosidade, encanta, surpreende; convida a reflexão, isto é, uma fase mais analítica e racional (CAMEROTTO; FORNASIER; ZABALZA-CERDEIRIÑA, 2017, p. 148, tradução nossa').

Durante o desenvolvimento da pesquisa foi possível observar nos relatos das professoras as estratégias utilizadas para controlar as crianças em relação às manifestações da sexualidade. Tal estratégia envolvia distraí-las com outras atividades ou brinquedos, mesmo entendo que esse processo é parte do conhecimento de si.

Isabella relata:

A criança não deve ser repreendida porque se não vai virar um tabu, uma coisa que não pode se masturbar. Eu acho muito cedo para uma criança de dois anos se masturbar, mas ele estava descobrindo o corpo dele, descobrindo que ele sentia prazer com aquilo que estava fazendo. O professor não pode proibir uma criança de dá prazer para

\footnotetext{
${ }^{7}$ No original: "Come fanno i bambini ad entrare nella pancia della mamma?”.

${ }^{8}$ No original: “[...] oggetti affettivi e strumenti di gioco e lo sfondo integratore [...]".

${ }^{9}$ No original: "[...] un modello di programmazione importantissimo nella scuola dell'infanzia in quanto fa sì che le esperienze avvengano all'interno di un ciclo emozionale che pone in relazione i desideri (attese, tensioni, motivazioni); può scuotere, smuovere dallo stato di quiete e di routine creando nuovi entusiasmi; facilita un incontro (con personaggi fantastici, una persona, un libro, un'azione); crea stupore come esperienza che incuriosisce, meraviglia, sorprende; invita alla riflessione, ciò̀ una fase più analitica e razionale".
} 
Josefina ressalta:

o seu próprio corpo. Nós nunca repreendemos ele de fazer isso, mas tentávamos chamar a atenção dele para outras coisas (ISABELLA).

\section{Josefina ressalta:}

É muito importante o professor não criticar esse ato porque não uma coisa errada. Algumas professoras acham isso feio, alguns pais acham isso errado, mas não é. Tem que tentar ensinar para a criança que há lugar próprios e impróprios para fazer isso. Explicar a diferença entre local público e privado e que não deve fazer na sala de aula, porque estará desviando o foco da atividade proposta pelo professor. Eu sei que para uma criança de um ano e meio é complicado ela entender o porquê que na sala de aula não pode e no quarto dela, por exemplo, pode se masturbar. $O$ interessante seria o professor chamar a atenção dessa criança para a atividade em sala de aula, assim ele distrai o pensamento (JOSEFINA).

Do mesmo modo, Maria argumenta:

Ano passado uma criança com menos de dois anos se masturbava e a minha atitude foi sempre conversar com ela, desviar a atenção para outra coisa, conversar com os pais. No entanto, os pais não acreditavam que isso era verdade, diziam que em casa a criança não fazia. Quando a criança se masturbava nos desviávamos a atenção dela para as brincadeiras, nunca chamávamos a atenção na frente dos coleguinhas, mas explicávamos que não podia fazer isso (MARIA).

Segundo Schindhelm (2013), é observável no âmbito educacional, às vezes, encontrar professoras vulneráveis, sem orientação e preparo para enfrentar os choques e os desafios relativos à sexualidade das crianças, isto faz com que as mesmas tenham condutam irregulares nesses momentos. Deste modo, pode-se perceber que o direito à curiosidade sexual, como nos exemplos citados é recusado à criança e impõe às professoras a necessidade permanente de um controle, através do redirecionamento da atenção para qualquer outro momento que desestimule e faça com que aquela ação seja esquecida pela criança.

Dentro do contexto escolar, as professoras são, a todo o momento, desafiadas a buscarem respostas para as suas inquietações relativas a questões da sexualidade, especialmente em relação às crianças pequenas. Schindhelm (2013, p. 5) afirma o quanto é complexo trabalhar com a sexualidade infantil, por se tratar de uma gama de aspectos peculiares, assim entende que: 
A sexualidade infantil apresenta-se na escola como um grande desafio pela transformação que promove na prática educativa, ao desvelar os ocultamentos e silenciamentos acerca da temática. Expressa por crenças, atitudes, valores, papéis e relacionamentos é produto de um trabalho permanente de ocultação, de dissimulação ou de mistificação na escola, um reflexo do que se produz da mesma forma na sociedade.

As crianças trazem para a sala de aula inúmeras situações e se manifestam das mais variadas maneiras, em torno da sua sexualidade. As crianças estão atentas ao mundo que as cerca, aprendem com ele, reproduzem e reinterpretam o que ocorre nos seus contextos. Além disso, as crianças têm corpos, que sentem, se afetam, são vivos, conseguem demonstrar o que as agrada, o que as desagrada, tem curiosidades acerca de si, do seu corpo e do corpo do outro. As professoras entrevistadas presenciaram situações, as quais a sexualidade era demonstrada. Isabella narra uma situação vivida por ela na sua prática pedagógica:

Tive um caso na sala de aula. O João ${ }^{10}$ com o passar do tempo começou a se masturbar na sala, mas claro chamamos a mãe para conversar sobre o assunto. Ela disse que ele fazia em casa também e ela não reprendia ele. Isso acontecia sempre na hora do soninho, quando ia deitar. Ele tinha uma coberta que trazia de casa, com isso ele tocava na região do pênis. Ele se esfregava até dormir. Ele era uma criança bem agitada, batia nos colegas (ISABELLA).

Diante dos casos de manifestação da sexualidade infantil, muitas vezes, como aconteceu nesse caso, o fato da criança tocar-se, é entendido como desvio, como um comportamento anormal, e, em certa medida associada ao estado de "agitação" da criança, como se as atitudes estivessem entrelaçadas. Uma tendência percebida em outra pesquisa em desenvolvimento relacionada ao tema, as professoras expressam que é comum ver as crianças tocando sua genitália e muito frequentemente associam esse ato com a suspeita de que em casa a criança presencie adultos fazendo sexo. Há, portanto, certa dificuldade de pensar que a mídia, a publicidade e a música exercem influência na construção da sexualidade.

As professoras precisam estar preparadas para lidar com o assunto, porém, negar ou repreender a criança por estar fazendo isso é uma atitude inadequada. Segundo Laviola (2006), é comum que o adulto, ao perceber algum comportamento na criança relacionado à manifestação da sexualidade, tenha alguma atitude. As atitudes são de variadas formas como: respondendo o questionamento da criança, informando-a, negando a existência da sexualidade, mentindo ou omitindo algumas questões. Portanto, o adulto precisa explicar e

\footnotetext{
${ }^{10}$ Todos nomes citados ao longo do artigo são fictícios.
} 
conversar com a criança sobre o que ela está passando e entender que é um processo que faz parte do desenvolvimento humano.

A partir dos relatos da professora pode-se perceber que os pais não repreendiam a criança por estar se masturbando, talvez por compreenderem que era uma curiosidade daquele momento. É preciso considerar o momento em que a criança toca a região genital: é o momento do "soninho". Esta característica também foi perceptível durante a atuação de uma das autoras em seu estágio extracurricular. Diante da rigidez das rotinas impostas às crianças nas escolas o ato de se tocar tenha sido, talvez, umas das formas de tornar aquele momento menos desagradável. Outro ponto a se destacar é a necessidade de um diálogo entre escola e família. Para Louro (2008) é importante existir este diálogo, pois dessa forma o trabalho voltado para a educação da criança se tornará abrangente e consolidado.

A professora Maria relata:

O caso que eu trabalhei ano passado não era apenas o conhecer, dava para perceber que havia algo de errado naquela criança, muitas vezes ficávamos nos olhando entre professoras e nos questionando que atitudes que deveríamos ter (MARIA).

Assim, percebe-se que a professora Maria tem uma concepção diversa da dos autores, pois, para ela, a manifestação da sexualidade não é considerada normal, deste modo, ela não compreende a manifestação da sexualidade como um aspecto relacionado à curiosidade das crianças. A professora menciona que o caso que presenciou não era apenas o conhecer, ela considerava que havia algo "errado na criança", o qual não soube explicar o que era. É perceptível como as manifestações da criança que está explorando seu próprio corpo, conhecendo-o, é visto como problema. As manifestações da sexualidade infantil na escola exigem que as professoras possuam conhecimentos e habilidades para tratar o tema, já que ele é silenciado até mesmo nos cursos de formação de professores. Para muitos, lidar com a sexualidade é um problema, já que não sabem ou não aprenderam como abordar tal assunto e acabam negando e repreendendo a criança (LAVIOLA, 2006).

Segundo Laviola (2006) diante dos comportamentos sexuais das crianças, as professoras relatam não se sentirem confortáveis ou preparadas para lidar de maneira natural. Assim, Maria descreve que, diante do caso que presenciou as professoras ficavam sem saber que atitudes tomar quando a criança manifestava sua sexualidade. As autoras Laviola (2006) e Ribeiro (2009) sugerem que nestes momentos pode-se solicitar que a criança faça isso em um lugar mais reservado, pois isso está relacionado com a sua intimidade. 
Para Ribeiro (2009) há variadas manifestações sexuais entre as crianças. Os aspectos mais comuns, tanto no ambiente escolar, como familiar, provêm das curiosidades, dos questionamentos, podendo ou não haver masturbação infantil. A masturbação infantil é marcada, na maioria das vezes, pela exploração do corpo, no qual, correspondendo a um estímulo corporal imediato e não às representações subjetivas de fantasias eróticas adultizadas.

Schindhelm (2013) ressalta que no momento que as professoras são questionadas sobre sexualidade pelas crianças, as mesmas entram em conflito em decorrência do seu desconhecimento, com a sua cultura e com os seus medos sobre sexualidade. Assim, percebese que as professoras se sentem desconfortáveis e desafiadas na busca de respostas para as inquietações das crianças e frequentemente pensam que há algum problema com a criança. Esse desconforto normalmente é pela falta de formação e oportunidade para discutir sobre o tema. A autora Schindhelm (2013, p. 8) baseados nos estudos de Foucault certifica que:

A prática docente na educação infantil lida, no dia-a-dia, com experiências problemáticas que levam os educadores a decisões num terreno de grande complexidade, incerteza, singularidade e de conflito de valores relativos ao sexual, quando deparam-se com situações oriundas das crianças regidas por uma "vontade de saber".

O desenvolvimento da sexualidade infantil está marcado fortemente pela história e pela cultura de determinada sociedade. $\mathrm{O}$ modo como os adultos reagem às explorações da sexualidade infantil está relacionado com a cultura de cada indivíduo, pois esse é um dos maiores aspectos que influencia no modo como estes reagem ao observar cenas desta natureza (BRASIL, 2009).

A manifestação da sexualidade pode aparecer durante qualquer momento, inclusive nas brincadeiras feitas pelas crianças. Esse fato é ressaltado por Josefina, a qual afirma:

Posso fazer uma ligação entre brincadeira e masturbação. $O$ professor tem que perceber se aquele ato de masturbação é uma brincadeira, ou a criança viu alguém fazendo aquilo, às vezes de alguma forma a criança está sendo estimulada em casa a fazer isso e reproduz isso através da brincadeira (JOSEFINA).

Segundo Constantine e Martinson (1984) é comum as professoras terem a ideia de que tal comportamento seria oriundo de repetições do ato sexual de algum adulto, presenciado pela criança, muitas vezes esquecendo que a mídia exerce grande influência nas crianças. A 
professora Josefina faz uma ligação entre brincadeira e masturbação, mas argumenta que cabe ao professor observar se este comportamento é apenas brincadeira ou se a criança está reproduzindo algo que presenciou. Assim, Josefina parece vincular a sexualidade a estímulos recebidos pelas crianças. Sem negar a presença desses provenientes da mídia, em especial, a sexualidade é primeiramente parte constituinte dos seres humanos. Conforme Laviola (1998, p. 45) "[...] conhecer o corpo nu da outra criança, descobrir as diferenças, conhecer o próprio corpo, tocar-se e experimentar sensações novas, tudo isso compõe a sexualidade infantil e faz parte do desenvolvimento sadio das crianças".

A psicóloga Marta Magalhães (2010) ressalta que a masturbação pode ser mais frequente quando a criança está triste, sonolenta ou muito tensa. Este comportamento proporciona, além de prazer, um alívio da tensão. A partir dos relatos trazidos pela professora Isabella, podemos perceber que a masturbação pode estar envolvida com alguns sentimentos, os quais já foram mencionados. Assim, Isabella ressalta:

Toda vez que chegava na hora de dormir o João pegava sua coberta e se esfregava. Parece que ele não gostava de dormir, mas era necessário que dormisse porque os colegas iam dormir e se ele ficasse acordado iria acordar todo mundo (ISABELLA).

Muitas vezes, é a imposição da rotina escolar leva a criança a experimentar outras formas de brincar, ou seja, “já que não posso brincar com os brinquedos e com meus colegas, brinco comigo mesmo, com meu corpo que também é uma fonte de prazer". Para Barbosa (2000) a rotina ajuda a criança a se organizar e saber a sequência das atividades diárias. Porém, a rotina não pode ser imposta a criança, pois através dessa "obrigação" de fazer tal atividade a criança fica ansiosa, podendo buscar outras formas de suprir esse desconforto gerado. Barbosa (2000) ainda destaca que no ambiente escolar, muitas vezes, percebe-se a rotina como forma de controle de classes, corrompendo a imaginação das crianças, criando indivíduos sem a coragem de experimentar o novo.

Dessa forma, pode-se perceber que as professoras produzem seus próprios conhecimentos relacionados à manifestação da sexualidade infantil, talvez, por não terem estudado e nem refletido sobre o porquê a criança está agindo desta forma. É relevante ressaltar que as professoras dizem concordar com a ideia de sexualidade, porém não deixam as crianças explorá-la, criando estratégias para este momento não existir ou seja esquecido pela criança. Vinculam-se ainda a sexualidade como problema, negando que a manifestação da sexualidade infantil faz parte do desenvolvimento sadio da criança. 
A forma de encarar os desafios, encontrados em torno da temática da sexualidade infantil, é o aprofundamento dos estudos, a busca constante por autores/as que pesquisam, estudam, escrevem e discutem o tema. Sendo assim, não existe uma receita da forma correta de como trabalhar com a sexualidade infantil, porém o silêncio e a repreensão não podem ser destaques dentro de uma sala de aula. Para as professoras é importante que haja espaços para discussões e momentos de reflexões sobre a temática, pois assim vão aos poucos lapidando seus conceitos relacionados ao tema.

\section{Para finalizar e seguir pensando}

Ao longo desta pesquisa pode-se perceber que a temática precisa ser discutida com ênfase para que o conhecimento produzido pelas professoras ultrapasse o senso comum. Dessa forma, a sexualidade infantil resultaria, talvez, em uma quebra de tabus e preconceitos, e se tornaria um aspecto mais problematizado pela sociedade e pelos contextos educativos.

No entanto, percebeu-se que as professoras se sentem despreparadas para lidar com situações desta natureza, ficando, muitas vezes, constrangidas e sem saber o que fazer ao presenciar uma criança descobrindo seu corpo ou mostrando-se curiosa em relação ao corpo do outro, especialmente quando as crianças percebem que anatomicamente meninos e meninas são diferentes, ou quando em alguns momentos se masturbam. Por isso, podem-se considerar importantes ações de pesquisa e extensão nas escolas, buscando problematizar os aspectos da sexualidade que aos poucos são ocultados, e promovendo a construção de novos conhecimentos.

Pode-se destacar que as professoras participantes da pesquisa agem, muitas vezes, a partir de suas concepções adultocêntricas em relação à manifestação da sexualidade infantil. Deste modo, as mesmas sentem-se desconfortáveis diante do desconhecido, talvez, envergonhadas, diante da presença da sexualidade infantil. Na maioria das vezes, as professoras agem por impulso e necessitam de improvisos para direcionar a ocasião em que a criança está manifestando a sua sexualidade. A despreparação das professoras pode estar ocorrendo, pela prática quase que inexistente de espaços abertos para a discussão sobre sexualidade durante o período de formação inicial e continuada. Sem esses espaços, as mudanças em torno da temática ficam ainda mais difíceis de serem abrangidas, ocorrendo silenciamento e a negligência como formas de encarar a situação.

É possível perceber, através de políticas públicas que trazem a sexualidade como um tema transversal, que precisa ser discutido dentro das escolas pelas professoras, no entanto, 
isso se torna precário, já que, muitas professoras não têm domínio e conhecimento do tema para conversar com as crianças. Durante o desenvolvimento da pesquisa foi possível observar que as professoras dizem concordar com a ideia de sexualidade, porém não têm clareza de como agir com as crianças, criando estratégias para que este momento não exista ou seja esquecido. Entendemos, de acordo com os autores estudados que a sexualidade faz parte do sujeito desde antes do nascimento e faz parte do desenvolvimento sadio da criança. As professoras possuem uma gama de visões sobre o assunto, nem sempre compreendendo que a sexualidade faz parte do desenvolvimento das crianças.

Acredita-se no diálogo sobre sexualidade infantil entre as docentes, pois dessa forma há possibilidade de ocorrer uma gradativa desconstrução de padrões tradicionais e preconceituosos relacionado ao assunto e a possibilidade de tratar com mais tranquilidade o tema que diz muito sobre nós mesmos, bem como reafirmar a necessidade de discussão do tema no âmbito das políticas públicas voltadas a educação.

\section{REFERÊNCIAS}

BRASIL. Resolução n 5, de 17 de dezembro de 2009. Fixa as Diretrizes Curriculares Nacionais para a Educação Infantil. Diário Oficial da União, Poder Executivo, Brasília, DF, 18 dez. 2009. Disponível em:

$<$ http://portal.mec.gov.br/index.php?option=com_docman\&view=download\&alias $=2298$ rceb005-09\&category_slug=dezembro-2009-pdf\&Itemid=30192>. Acesso em: 07 jun. 2017.

BARBOSA, Maria Carmem Silveira. Por amor \& por força: rotinas na educação infantil. 2000. 283 p. Tese (Doutorado em Educação)-Universidade Estadual de Campinas, Campinas, 2000.

BRITZMAN, Deborah. Sexualidade e cidadania democrática. In: SILVA, Luiz Heron. A escola cidadã no contexto da globalização. Petrópolis: Vozes, 1998, p.154-171.

CAMEROTTO, Laura; FORNASIER, Giuliana; ZABALZA-CERDEIRIÑA, Maria Ainoa. La vita è bella... La nascita di un bambino, na nascita di una bambina. RELAdEI, Santiago de Compostela, v. 6, n. 1-2, p.141-157, jan./jul. 2017.

CLANDININ, D. Jean; CONNELLY, F. Michael. Pesquisa narrativa: experiências e história na pesquisa qualitativa. Tradução por Grupo de Pesquisa Narrativa e Educação de professores ILEEL/UFU. 2. ed. Uberlândia: EDUFU, 2015.

CONSTANTINE, Larry L.; MARTINSON, Floyd M. Sexualidade infantil: novos conceitos, novas perspectivas. São Paulo: Roca, 1984. 
EDWARDS, Carolyn; GANDINI, Lella; FORMAN, George. As cem linguagens da Criança: a experiência de Reggio Emilia em transformação. Porto Alegre: Penso, 2016, v. 2.

FOUCAULT, Michel. História da Sexualidade I: A vontade de saber. Rio de Janeiro: GRAAL, 1988.

FREUD, Sigmund. Obras Completas: três ensaios sobre a sexualidade. Rio de Janeiro: Imago, 1969, v. 7.

GIL, Antônio Carlos. Como elaborar projetos de pesquisa. 4. ed. São Paulo: Atlas, 2002.

LAVIOLA, Elaine Cardia. Reações de educadoras de creche diante de manifestações de sexualidade infantil. In: Seminário Internacional Fazendo Gênero, 7., 2006. Anais... Florianópolis: UFSC, Editora mulheres, 2006.

LAVIOLA, Elaine Cardia. Sexualidade infantil: o relato de educadoras de creche frente as manifestações das crianças. 1998. Dissertação (Mestrado em Psicologia Social)-Pontifícia Universidade Católica de São Paulo, São Paulo, 1998.

LOURO, Guacira Lopes. Pedagogias da Sexualidade. In: LOURO, Guacira Lopes (Org.). O corpo educado: pedagogias da sexualidade. Tradução de Tomaz Tadeu da Silva. Belo Horizonte: Autêntica, 2000. p. 4-24. Disponível em:

$<$ https://repositorio.ufsc.br/bitstream/handle/123456789/1230/Guacira-Lopes-Louro-OCorpo-Educado-pdf-rev.pdf> . Acesso em: 20 jan. 2018.

LOURO, Guacira Lopes. Gênero, sexualidade e educação: Uma perspectiva pósestruturalista. 10. ed. Petrópolis: Vozes, 2008.

MAGALHÃES, Marta. Masturbação Infantil. Blog Psicóloga Marta Magalhães. Disponível em: <http://psicologamartamagalhaes.blogspot.com.br/2010/08/masturbacao-infantil.html >. Acesso em: 22 fev. 2016.

MELUCCI, Alberto. Busca de qualidade, ação social e cultura: por uma sociologia reflexiva. In: MELUCCI, Alberto (Org.). Por uma Sociologia Reflexiva: pesquisa qualitativa e cultura. Tradução por Maria do Carmo Alves do Bonfim. Petrópolis: Vozes, 2005, p. 25-42.

MINAYO, Maria Cecília de Souza. Pesquisa social: teoria, método e criatividade. 12. ed. Petrópolis: Vozes, 2001.

RIBEIRO, Marcos. Conversando com seus filhos sobre sexo. São Paulo: Editora Academia de Inteligência, 2009.

SCHINDHELM, Virginia Georg. Concepções e práticas dos educadores sobre sexualidade e gênero na educação infantil. 2013. 219 p. Tese (Doutorado em Educação)-Universidade Federal Fluminense, Niterói, 2013.

WEEKS, Jeffrey. O corpo e a sexualidade. In: LOURO, Guacira Lopes (Org.). O corpo educado: pedagogias da sexualidade. Tradução do artigo por Tomaz Tadeu da Silva. 2. ed. Belo Horizonte: Autêntica, 2000, p. 24-61. Disponível em: 
<https://repositorio.ufsc.br/bitstream/handle/123456789/1230/Guacira-Lopes-Louro-O-

Corpo-Educado-pdf-rev.pdf> . Acesso em: 20 jan. 2018.

\section{$\underline{\text { SOBRE OS AUTORES }}$}

\section{Litiéli Wollmann Schutz}

Mestranda em Educação pela Universidade Federal de Santa Maria (UFSM). Membro do grupo de pesquisa Filosofia, Cultura e Educação (FILJEM). Email: litieli.wollmann62@gmail.com

\section{Lucas da Silva Martinez}

Doutorando em Educação pela Universidade Federal de Santa Maria (UFSM). Email: lukasspedagogia@gmail.com

\section{Sueli Salva}

Doutora em Educação pela Universidade Federal do Rio Grande do Sul (UFRGS). Pósdoutorado pela Universidade de Milão (UNIMI-Itália). Professora do Programa de PósGraduação em Educação da Universidade Federal de Santa Maria (UFSM). Email: susalvaa@gmail.com 